\title{
Os Espanhóis Canibais: análise das gravuras do sétimo volume das Grands Voyages de Theodore de Bry ${ }^{1}$
}

Luis Guilherme Assis Kalil ${ }^{2}$

$\mathrm{O}$ artigo analisa as ilustrações feitas por Theodore de Bry e seus descendentes para as Grands Voyages, coleção de relatos sobre o Novo Mundo publicada entre o final do século XVI e início do XVII. A partir do sétimo volume, dedicado à Viaje al Río de la Plata, do soldado bávaro Ulrico Schmidl, buscamos analisar as representações dos indígenas e dos espanhóis presentes nas imagens feitas pelo editor protestante.

Palavras-chave: Theodore de Bry, Novo Mundo, Canibalismo.

The Cannibal Spaniards: analysis of the engravings of the seventh volume of Theodore de Bry's Grands Voyages

The article analyses the images done by Theodore de Bry and their descendants for the Grand Voyages, collection of reports about the New World published between the 16th and the 17th Centuries. From the seventh volume, dedicated to the Viaje al Río de la Plata, from the bavarian soldier Ulrico Schmidl, we seek to analyze the representations of the Indians and of the Spaniards that were presented in the images done by the protestant editor.

Keywords: Theodore de Bry, New World, Cannibalism.

\footnotetext{
${ }^{1}$ Artigo recebido em junho de 2010 e aprovado para publicação em dezembro de 2010.

${ }^{2}$ Doutorando em História Cultural pela Universidade Estadual de Campinas. E-mail: lgkalil@ yahoo.com.br
} 


\section{Les Espagnols Cannibales: analyse des gravures du septième tome des Grands Voyages de Theodore de Bry .}

Larticle analyse les illustrations faites par Theodore de Bry et leurs descendants pour les Grands Voyages, collection de rapports sur le Nouveau Monde publié entre la fin du XVIe siècle et le début du XVIIe. À partir du septième tome, dédié à Viaje al Río de la Plata, du soldat bavarois Ulrico Schmidl, on cherche à analyser les représentations des indigènes et des espagnols présents dans les images faites par l'éditeur protestant.

Mots-clés: Theodore de Bry, Nouveau Monde, Cannibalisme.

\section{As Grands Voyages de Theodore de Bry}

Da mesma maneira que a palavra e o texto, a imagem pode, a seu modo, ser o veículo de todos os poderes e de todas as resistências. O pensamento que ela desenvolve oferece uma matéria específica, tão densa como o texto, mas que costuma ser irredutível a ele, o que não facilita nada a tarefa do historiador obrigado a atribuir palavras ao indizível.

Serge Gruzinski

O contato dos europeus com o Novo Mundo e o Oriente, a partir de meados do século XV, intensificou o interesse por narrativas de viajantes, o que estimulou editores a publicarem coletâneas de relatos sobre estas terras ${ }^{3}$. Entre eles, destaca-se Theodore de Bry, para quem: "seria de fato de estranhar se encontrássemos uma pessoa de juízo que não tivesse vontade e prazer de se informar a respeito dessas paisagens longínquas, de povos bárbaros, de seus costumes, suas vidas, religião e policiamento" 4 .

Descendente de ourives, Theodore de Bry nasceu em Liège, em 1528, mas, por defender a Reforma e combater a intervenção espanhola na região, foi obrigado a abandonar sua cidade natal. Estabeleceu-se em Estrasburgo (grande centro editorial e de atração de protestantes perseguidos), onde trabalhou para o

\footnotetext{
3 Já em 1483, Geradt Leuv reuniu e publicou os relatos de Marco Pólo, Jean de Mandeville e Ludolpe Suchan. Entretanto, segundo Defert, foram as coleções de Ramusio (Navigationi e Viaggi) e de Richard Hakluyt (The Principal Navigations, Voiages, Traffiques and Discoveries of the English Nation) as que mais se destacaram ao longo do século XVI. Daniel Defert, "Collections et Nations au XVIe siècle”, Michèle Duchet (org.), L’Amérique de Théodore de Bry - une collection de voyages protestante du XVIe siècle, quatre études d'iconographie, Paris: CNRS, 1987, p. 49.

${ }^{4}$ Apud Zinka Ziebell, Terra de Canibais, Porto Alegre, Editora Universidade/UFRGS, 2002, p. 120.
} 
também refugiado artista huguenote Etienne Delaune ${ }^{5}$. Nesse período, viajou à Inglaterra, onde conheceu Richard Hakluyt, editor de uma compilação de narrativas de viajantes que o encorajou a lançar a sua própria coleção ilustrada.

A partir das obras de Thomas Hariot e Jacques le Moyne de Morgues, obtidas através do editor inglês ${ }^{6}$, de Bry iniciou, em 1590, a publicação de seu principal projeto editorial, que recebeu o título de Thesaurus de Viagens ou Collectiones Peregrinatorum in Indiam Occidentalem et Indiam Orientalem. Contudo, sua coleção ficou mais conhecida pela divisão feita entre as Grands Voyages (formato in-folio e dedicada às narrativas sobre a América) e as Petit Voyages (formato menor e referente às Índias Orientais) ${ }^{7}$.

Primeira coletânea sobre o Novo Mundo publicada em diversos idiomas, as Grands Voyages foram um sucesso editorial durante aproximadamente quatro décadas ${ }^{8}$, compondo um total de treze volumes em latim e quatorze em alemão (os dois primeiros livros também tiveram edições lançadas em inglês e francês).

Para a elaboração de suas ilustrações, de Bry utilizou a técnica da gravura em cobre, que permitia uma maior riqueza de detalhes. No entanto, era mais cara e, por isso, ainda pouco presente nas coleções de crônicas, que utilizavam, em geral, a xilogravura. O emprego de uma técnica inovadora, a escolha de temas polêmicos para serem retratados (como o canibalismo e a idolatria) além de inovações no processo de reprodução e impressão geraram um grande impacto visual, chegando a influenciar as obras de outros artistas ${ }^{9}$. Para Belluzzo, o ambicioso pro-

\footnotetext{
${ }^{5}$ Além de Delaune, de Bry foi influenciado por Albrecht Dürer, artista fortemente marcado pelas inovações da arte italiana do período e pelas noções matemáticas e estudo das proporções dos corpos humanos. São também apontadas como ponto de partida para suas ilustrações as gravuras presentes nos relatos de André Thévet (1557) e de Jean de Léry (1578).

${ }^{6}$ É importante destacarmos a escassez de fontes disponíveis para os editores durante os séculos XVI e XVII. Muitos relatos tiveram suas publicações proibidas pelas Coroas europeias e pela Igreja Católica.

${ }^{7}$ Afora as duas coleções de viagens, os de Bry também editaram outros livros, imagens bíblicas, alegorias e retratos, formando um "acervo com clara vocação enciclopédica". Janice Theodoro, "Colombo, Alegorias e Revelações", A Escrita da Memória - interpretações e análises documentais, São Paulo, 2004, p. 99.

${ }^{8} \mathrm{O}$ último tomo da coleção foi publicado em 1634, por Mattäus Merian e Guilhaume Titzer (genros dos filhos de Theodore).

${ }^{9}$ Tatsch indicou a influência do "vocabulário iconográfico" criado por de Bry em alegorias de continentes, em artistas como Charles Le Brun e até em clérigos católicos, como o austríaco Philoponus.
} 
jeto gráfico da coleção "marca o momento em que o argumento visual toma proeminência e conquista autonomia com relação ao texto, do qual se desgarra" ${ }^{10}$.

É preciso ressaltar que o continente europeu nos séculos XVI e XVII, mesmo nas regiões protestantes, permanecia com altas taxas de analfabetismo, o que fortalecia a difusão das ilustrações e sua influência na leitura dos relatos onde estavam inseridas ${ }^{11}$. A imagem foi impulsionada ainda mais com a possibilidade de reprodução mecânica, que, segundo Gruzinski, representou "uma revolução midiática sem precedente, de alcance comparável à difusão do impresso"12, fazendo com que, em muitos casos, as gravuras tivessem um impacto maior do que o do próprio texto em que estavam inseridas ${ }^{13}$.

Várias destas ilustrações sobre o Novo Mundo continuam sendo reproduzidas atualmente em livros didáticos e periódicos. Contudo, na maioria das vezes, são incluídas não como representações de um artista europeu, mas sim como retratos fiéis do período ${ }^{14}$. Parte da historiografia também analisou as ilustrações dessa maneira, afirmando que, através delas, seria possível obter "informações etnográficas" sobre os indígenas e a natureza, como Alexander ${ }^{15}$, Bouyer e Duviols ${ }^{16}$. Para

Flavia Galli Tatsch, "Da palavra à imagem: a alegoria da América no imaginário europeu”, Ideias, vol. 13, n. 2, Campinas, 2006, pp. 46-51.

${ }^{10}$ Ana Maria de Moraes Belluzzo, O Brasil dos Viajantes - vol. I, São Paulo, Metalivros, 1999, p. 53.

${ }^{11}$ Eisenstein afirma que os protestantes foram pioneiros na exploração da imprensa como meio de massa e das gravuras como veículo de propaganda, seguidos pela Igreja Católica que, com o Concílio de Trento, também estimulou o uso das imagens para a ação evangelizadora. Apud Yobenj Aucardo Chicangana-Bayona, "Do Apolo de Belvedere ao Guerreiro Tupinambá: Etnografia e convenções renascentistas”, História, vol. 25, n. 2, São Paulo, 2006, p. 17.

${ }^{12}$ Serge Gruzinski, A Guerra das Imagens: de Cristóvão Colombo a Blade Runner (1492 - 2019), São Paulo, Companhia das Letras, 2006, pp. 101-108.

${ }^{13}$ Como exemplo, podemos citar a Brevísima Relación de destrucción de las Indias, de Las Casas. Para Carbia as gravuras feitas por de Bry são mais importantes que a própria narrativa para explicar a disseminação da "legenda negra" nas regiões protestantes. Romulo Carbia, Historia de la Leyenda Negra Hispanoamericana, Madrid, Consejo de la Hispanidad, 1944, p. 81.

${ }^{14}$ Freire apontou a recorrência da utilização das ilustrações feitas por de Bry, indicando que, em muitos casos, "as imagens desgarram-se de tal forma de seu conteúdo que servem para evidenciar qualquer massacre". Deolinda de Jesus Freire, A eficácia narrativa da "Brevíssima relación de destrucción de las Indias" na propagação da "leyenda negra" anti-hispânica, São Paulo, USP, 2004, p. 121.

15 "De Bry did not let his decorative urge overwhelm his historical integrity (...) where imagination was called for it was kept in check". Michael Alexander, Discovering the New World, London, London Editions, 1976, p. 10.

${ }^{16}$ Para estes autores o editor se afastou da "imaginação e da fantasia" fazendo com que suas imagens se tornassem "un document ethnographique de premier ordre". Marc Bouyer e Jean-Pierre Duviols, 
eles, apesar de nunca ter saído da Europa, de Bry copiou "detalhes 'etnográficos' 'registrados' pelos artistas e gravuristas em que baseou suas imagens"17.

No entanto, segundo Laura de Mello e Souza, não havia no período uma busca dos artistas por uma representação do "real" do novo continente. Vários dos denominados "detalhes etnográficos" remetiam a elementos da cultura europeia e eram repetidos em ilustrações de diferentes regiões: "não se representava o que se tinha diante dos olhos, mas o que era possível e lícito representar, segundo normas e cânones muito bem fixados" ${ }^{\prime 18}$.

O fato de não centrarmos nossa atenção na busca por informações etnográficas nas ilustrações não nos remete, contudo, ao extremo oposto de encará-las como algo independente dos textos que acompanham. Procedimento presente em livros como La Sauvage aux seins pendants, de Bernadette Bucher, onde as ilustrações são interpretadas como uma "mitologia não verbal"19.

As relações entre texto e imagem foram analisadas por Janice Theodoro, que apontou três "indicadores" importantes para compreendermos a obra de Theodore de Bry: "1. o olhar do narrador ao selecionar imagens e textos (considerando que de Bry sofreu perseguição religiosa); 2. os temas e autores selecionados; 3. a forma de organização, reordenação e cópia de cada um dos elementos da imagem"20. Como apontado pela historiadora, além de ilustrar, os editores também traduziam e alteravam os textos que lhes serviam como base, buscando, de diversas maneiras, direcionar o olhar do leitor e impor sua interpretação da obra. Esse processo também foi apontado por Chartier, para quem "as próprias estruturas do livro são dirigidas pelo modo de leitura que os editores pensam ser o da clientela almejada"21.

Le Théatre du Nouveau Monde, Paris, Gallimard, 1992, pp. 130 - 198.

${ }^{17}$ Chicangana-Bayona, op. cit., 2006, p. 43.

${ }^{18}$ Apud Ronald Raminelli, Imagens da Colonização: a representação do índio de Caminha a Vieira, Rio de Janeiro, Jorge Zahar Editora, 1996, p. 9.

${ }^{19} \mathrm{O}$ método adotado por Bucher foi criticado por historiadores como Duchet: "[na obra de Bucher] le système des images ne communique pas avec les réseaux du texte et la 'vraie' lecture de l'image se fait par l'image". Duchet, op. cit., p. 39.

${ }^{20}$ Theodoro, op. cit., p. 102.

${ }^{21}$ Roger Chartier, A ordem dos livros - leitores, autores e bibliotecas na Europa entre os séculos XIV e XVIII, Brasília, Editora da UNB, 1994, pp. 19-20. 
Entre outras estratégias, podemos apontar o agrupamento de crônicas em um mesmo volume, a "correção" do conteúdo através da comparação de relatos, a criação ou modificação dos títulos, os critérios utilizados para a escolha das passagens a serem ilustradas, a reutilização de antigas gravuras, entre outras. A publicação da Brevísima Relación de la Destrucción de las Indias é exemplar em relação à atuação dos editores. Como veremos adiante, a obra de Bartolomé de Las Casas foi utilizada como "munição" para ataques à atuação católica e espanhola no Novo Mundo. Entretanto, segundo Freitas Neto, as gravuras feitas por de Bry - que enfatizavam a destruição dos indígenas pelas mãos dos católicos espanhóis - não foram as únicas responsáveis pela amplificação e consagração do sentido trágico descrito pelo dominicano. As primeiras publicações da obra fora da Espanha apresentavam outros títulos, onde podemos perceber "uma visão superior à do próprio autor no que tange aos aspectos trágicos da Conquista"22.

Assim, buscamos neste artigo compreender como editores e artistas, que, muitas vezes, tinham contato com os indígenas apenas através das narrativas de viajantes, influenciados não apenas por estes relatos, mas também por sua formação artística e pela conflituosa situação política e religiosa por que passava a Europa, selecionaram as obras, os temas e os meios para representarem as novas terras e seus habitantes. Dessa forma, entramos no campo do que Roger Chartier denominou de "lutas de representações", que: "têm tanta importância como as lutas econômicas para compreender os mecanismos pelos quais um grupo impõe, ou tenta impor, a sua concepção do mundo social, os valores que são os seus, e o seu domínio"23.

\section{Americae Pars VII}

Antes da crônica de Schmidl, de Bry publicou duas obras relativas à parte norte do continente americano, que já possuíam ilustrações feitas por outros artistas (como as aquarelas de John White). Estas obras balizaram os modelos utilizados pelo editor para realizar as gravuras dos volumes seguintes, principalmente o terceiro, que contém as narrativas de Hans Staden e Jean de Léry. Os três volumes posteriores foram dedicados aos escritos de Girolamo Benzoni,

\footnotetext{
${ }^{22}$ José Alves de Freitas Neto, Bartolomé de Las Casas: a narrativa trágica, o amor cristão e a memória americana, São Paulo, Annablume, 2003, pp. 121-212.

${ }^{23}$ Roger Chartier, A História Cultural entre práticas e representações, Lisboa, Difel, 1990, p. 17.
} 
acrescidos de comentários do teólogo protestante Urbain Chauveton, que faz severas críticas ao comportamento dos espanhóis no Novo Mundo ${ }^{24}$. Lestringant apontou uma continuidade entre as ilustrações dos relatos de Benzoni e Schmidl: ambas mostraram os espanhóis, "pretensos civilizadores", praticando atos mais bárbaros que os indígenas ${ }^{25}$.

Dedicado ao relato de Ulrico Schmidl, o sétimo tomo da coleção ${ }^{26}$ foi publicado em alemão no ano de $1597^{27}$, pouco antes da morte de Theodore de Bry ${ }^{28}$. Nele, o soldado bávaro, que permaneceu durante quase duas décadas na América (1536 - 1553), descreve os primeiros contatos dos europeus com a natureza e os indígenas da região sul do novo continente.

Após o relato de Schmidl, a coleção publicou autores de diversas origens, como o inglês Francis Drake, o jesuíta Joseph de Acosta, o cronista espanhol Antonio de Herrera y Tordesillas, entre outros. A sequência de nomes demonstra que as Grands Voyages formavam um material heterogêneo, que o editor buscou adaptar, de diversas maneiras, a um público majoritariamente protestante ${ }^{29}$. Com isso, percebemos que, além das próprias crônicas e de alguns cânones artísticos do período, as gravuras feitas por de Bry e seus descendentes eram também influenciadas por textos e imagens presentes em outros volumes da própria coleção.

Ao analisarem as gravuras das Grands Voyages, os historiadores são praticamente unânimes em apontar que as perseguições religiosas sofridas pelo editor

\footnotetext{
${ }^{24}$ Segundo Cárcel, os espanhóis foram retratados por Benzoni como "sujos, ingratos e traidores" e a conquista como "una campaña de saqueo y extermínio". Ricardo García Cárcel, La Leyenda Negra: historia y opinión, Madrid, Alianza Editorial, 1998, pp. 271-275.

${ }^{25}$ Apud Duchet, op. cit., p. 96.

${ }^{26}$ Segundo Baumann o impacto das Grands Voyages decaiu após a publicação do sexto volume. Thereza B. Baumann, Notícia de uma coleção: as "Grandes Viagens" da família De Bry, disponível em: http://www.ifcs.ufrj.br/ humanas/0036.htm.

${ }^{27}$ O título completo do volume era: "Das VII Theil America / Warhaffige und liebliche / Beschreibung etlicher furnemmen / Indianischen Landschafften und Insulen / die vormals in keiner Chronicken gedacht, und erst- / lich in der Schiffart Ulrici Schmidts von Straubingen mit grosser gefahr erkundigt, un von / ihn selber auffs fleissigste beschrieben / und dargethan. / -Und an Tag gebracht durch Dietterich / von Bry. / - Anno M.D.XCVII. / - Venales reperiuntur in officina / Theodori de Bry".

${ }^{28}$ Dois anos depois, já sob o comando de Johan Theodor e Johan Israel (filhos do fundador), editouse uma versão em latim, com o título Americae Pars VII. A crônica de Schmidl foi retomada pelos de Bry em mais dois momentos: em 1625 há uma reedição e em 1631 ela integrou a compilação de relatos Historia Antipodum oder Newe Welt.

${ }^{29}$ Como exemplo, podemos citar a edição da Viagem à Terra do Brasil, de Jean de Léry, onde de Bry excluiu do prefácio do cronista todas as referências a Villegagnon e à França Antártica.
} 
protestante marcaram profundamente seu conteúdo, que, reiteradas vezes, retratam ataques ao comportamento dos espanhóis e católicos no Novo Mundo. Entre os autores que identificaram essa característica podemos citar Conley ${ }^{30}, Z^{2}$ iebell ${ }^{31}$, Duchet $^{32}$ e Cunha, para quem o "propagandista huguenote" publicou a obra de Schmidl, "provavelmente por atestar os péssimos hábitos dos conquistadores espanhóis, que chegam, entre outras coisas, a devorar enforcados quando a fome os aperta em Buenos Aires"33. Críticas estas que, além de remeterem à conturbada situação europeia do período, visavam estimular o comércio e a colonização protestante na América: "o empreendimento editorial incentivava os protestantes - grupo que até aquele momento estava excluído das novas áreas descobertas - a colonizarem a América" ${ }^{34}$.

Dessa maneira, notamos que há nestas ilustrações um inegável caráter crítico à atuação católica e espanhola no Novo Mundo. Entretanto, seu conteúdo não se limita a este aspecto. Janice Theodoro afirma que, até hoje, as análises sobre de Bry não deram atenção ao debate teológico que havia no período, a partir do qual se constituiu um novo projeto político que caracterizou o pensamento moderno: "trata-se de compreender a circunstância em que o homem, em consonância com a sua natureza, percebe-se livre, portanto capaz de interferir na vida política por intermédio de uma filosofia moral”. Para a autora, não há dúvidas de que o editor reprovava o comportamento espanhol e de que sua obra foi uma das grandes difusoras da leyenda negra, mas "ele ia muito além ao demonstrar com suas seleções de imagens sobre europeus e indígenas que a natureza, primeiro agente de Deus e benfeitora dos homens, havia colocado todos na mesma forma para demonstrar que éramos todos irmãos". Dessa forma, o grande tema das Grands Voyages seria a denúncia e o combate à intolerância. Theodoro indicou ainda que

\footnotetext{
30 "He sought previously published works that he could translate and then illustrate in the service of a protestant vision". Tom Conley, "De Bry's Las Casas", Amerindian Images and the Legacy of Columbus, Minneapolis, 1992, p. 104.

31 "[de Bry tinha como objetivo] publicar uma coleção para viajantes protestantes, anticatólica e anti-hispânica, que colocasse em evidência as atrocidades cometidas no Novo Mundo em nome do papa, que servisse à causa das nações protestantes". Ziebell, op. cit., p. 97.

32 "De Bry place toute la collection sous le signe de l'ideologie protestante". Duchet, op. cit., p. 26.

${ }^{33}$ Manuela Carneiro da Cunha, "Imagens de Índios do Brasil: o século XVI", Estudos Avançados, vol. 4, n. 10, São Paulo, 1990, pp. 91-110.

${ }^{34}$ Ronald Raminelli, “Eva Tupinambá”, História das Mulheres no Brasil, São Paulo, 2002, p. 39.
} 
de Bry buscava uma interlocução com setores do catolicismo, o que fica evidente através da publicação do relato de Acosta. Assim como o editor, o jesuíta combatia a imagem do indígena como um ser bruto e bestial e criticava a incapacidade dos espanhóis em perceber como viviam os nativos em meio às suas leis, com coisas bárbaras e sem fundamentos, mas que, muitas vezes, estabeleceram governos marcados pela ordem e pela razão ${ }^{35}$. Com isso, pretendemos demonstrar que ilustrações interpretadas como sinais inequívocos da barbárie dos nativos, também traziam consigo a defesa de que a necessária conversão era, não só possível, como desejada pelos indígenas.

\section{Os espanhóis canibais}

À narrativa de Schmidl foram incluídas quatro ilustrações, além do frontispício. A primeira delas retrata um porto europeu. No entanto, ela já havia sido publicada no terceiro livro da coleção. Tal repetição não era algo incomum no período, pelo contrário, em algumas ocasiões as imagens eram repetidas dentro de uma mesma obra, o que ocorre na própria Viaje al Río de la Plata. Ao republicá-la, em 1625, os descendentes de Theodore de Bry decidiram excluir a imagem que aborda a recepção pacífica dos Jerú aos espanhóis (ilustração 1) para repetir outra, que mostra dois indígenas inimigos sendo queimados em uma fogueira (ilustração 2). A utilização deste recurso reforça a inexistência da busca por uma "História natural" do Novo Mundo através das ilustrações. Características referentes a uma região ou a um grupo indígena podiam ser empregadas nas descrições de outros locais e tribos.

A repetição de gravuras dentro de um mesmo ou em diferentes volumes tinha como um de seus principais efeitos a produção de estereótipos, fazendo com que certas imagens transcendessem suas edições. Efeito visível através da ilustração que se repete nas capas do terceiro e do sétimo volumes da coleção, que mostra dois indígenas adorando um ídolo e também um grupo alimentando-se dos corpos de seus inimigos (ilustração 5). Nas palavras de Duchet: "Le caractère des frontispices apparaît en tout cas, au degré premier, valant non seulement pour

\footnotetext{
${ }^{35}$ Theodoro, op. cit., pp. 95-104.
} 
les textes de Staden ou de Léry, mais pour toute la collection et toute référence au cannibalisme dans les textes les plus divers"36.

Além do porto europeu, a primeira edição da Viaje al Río de la Plata feita por de Bry incluiu outras três gravuras. Uma delas retrata o modo como os espanhóis foram recepcionados pelos Jerú (ilustração 1). Ao analisarmos o relato de Schmidl, observarmos que, neste trecho ${ }^{37}$, ao contrário das outras descrições de contato com aldeias indígenas, o viajante impressionou-se com a recepção, elogiando os costumes dos Jerú e os aproximando do universo europeu. Já a ilustração contrapõe a festiva acolhida indígena com o aspecto dos espanhóis. Percebemos claramente as diferenças na postura dos dois grupos: os indígenas estão cantando e dançando, enquanto os espanhóis permanecem agrupados e conversando entre si; os índios, em sua maioria, seguram apenas instrumentos musicais (os poucos armados estão caçando), já os soldados permanecem com suas espadas e arcabuzes. Contudo, nenhum dos elementos é tão marcante quanto a postura dos líderes: o "rei” Jerú está sorrindo e oferecendo alimentos aos visitantes, já o chefe espanhol permanece em atitude hostil, portando seu bastão e sua espada.

\footnotetext{
${ }^{36}$ Duchet, op. cit., p. 22.

37 "cuando vinimos a una legua de camino a cercanías de la localidad, vino a nuestro encuentro el rey de los Jerús con doce mil hombres, más bien más que menos, en modo pacífico (...) el rey de los Jerús dirige su corte a su manera como un gran señor en estos países. Durante la mesa hay que tocar la música para él; (también) a medio día, si es ocurrencia del rey, los hombres y las mujeres más bellas deben bailar ante él. Cuando uno de nosotros los cristianos las ve bailar, uno ante esto se olvida entonces de cerrar la boca". Ulrich Schmidl, Derrotero y viaje a España y las Indias, Santa Fe, Universidad del Litoral, 1938, pp. 112-113.
} 


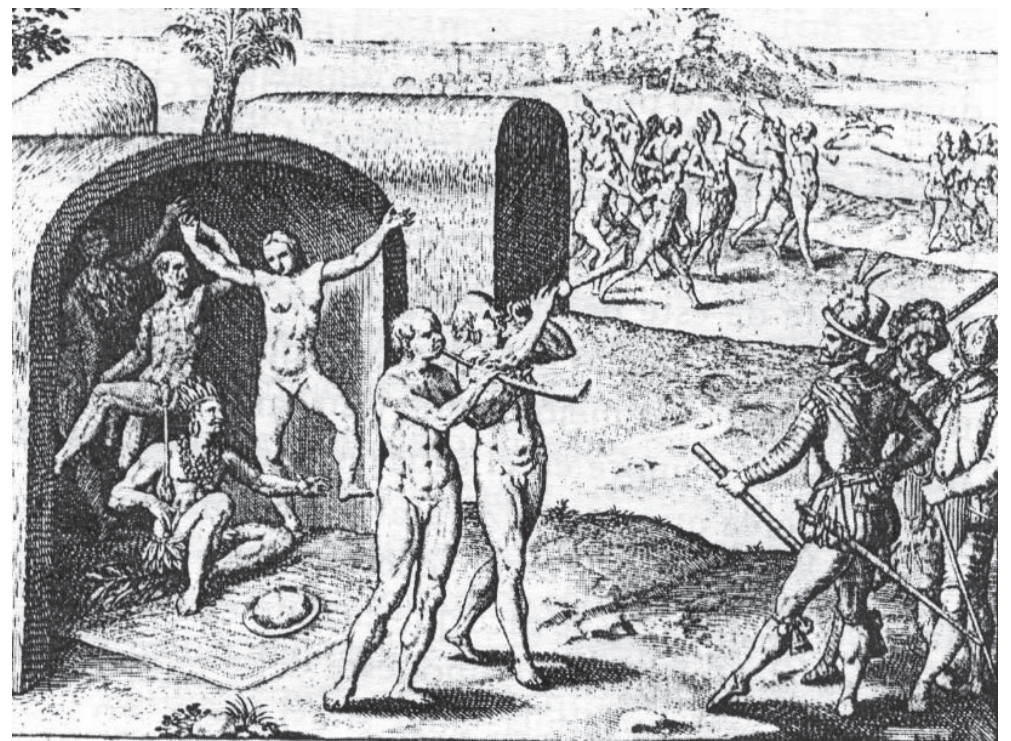

O modo como indígenas e espanhóis são retratados nesta ilustração evidencia os modelos presentes na coleção. Chicangana-Bayona afirmou que havia um cânone de beleza derivado de Alberti (do qual a estátua do Apolo de Belvedere seria o exemplo máximo), que foi desenvolvido por artistas como Albrecht Dürer e utilizado por de Bry. Utilização que seria comprovada através da repetição de modelos em etnias e culturas diferentes. Para o autor, não apenas os corpos, mas também suas ações e posturas respondiam a determinados cânones de representação preestabelecidos ${ }^{38}$. Voltando à imagem da recepção indígena, a postura do líder espanhol, com um pé à frente, é recorrente nas Grands Voyages e remete às ideias de nobreza e elegância, mas também de arrogância e desafio, indicando a intenção de tomar posse das terras.

Outro elemento importante da ilustração acima é a forma como de Bry retratou o cabelo dos indígenas, já que não há nenhuma referência ao tipo de corte usado pelos Jerú na obra de Schmidl. Segundo Raminelli, o editor era um profundo conhecedor dos textos que ilustrava, indicando que "a infidelidade aos

${ }^{38}$ Chicangana-Bayona, op. cit., 2006, p. 26. Para Belluzzo, o editor "não descuida da proporcionalidade e da posição das figuras, que se mostram estudadas a partir de cânones e motivos clássicos". Belluzzo, op. cit., p. 57. 
relatos permite decifrar alguns caminhos percorridos pelo artista" ${ }^{39}$. Analisando os volumes anteriores da coleção, notamos que a imagem dos nativos com cabelos apenas na parte anterior da cabeça está presente pela primeira vez no terceiro livro. Mais especificamente, ela se refere à obra de Hans Staden, para quem os Tupinambá "fazem uma tonsura, como um monge". O autor afirmou ainda que, ao perguntar onde eles aprenderam isso, recebeu a resposta de que seus antepassados tinham visto esse cabelo em um homem chamado "Meire Humane", que "havia feito muitas maravilhas entre eles. Têm-no por um profeta ou apóstolo" 40.

A possível presença de um "profeta" entre os índios antes da chegada dos europeus certamente impactou os leitores. Indícios como este apontariam um contato anterior com o cristianismo, o que não só comprovaria a humanidade dos nativos, mas também a sua possibilidade de conversão. De Bry certamente se interessou por esta passagem, o que se comprova durante a análise dos volumes posteriores de sua coleção. Não apenas as gravuras de Staden e Schmidl apresentam indígenas com o cabelo "tonsurado", mas também as existentes nas edições das narrativas de Léry, Benzoni, Acosta, entre outros. A partir deste elemento, observamos, novamente, que não havia no editor a preocupação de realizar uma representação "etnográfica" dos nativos americanos, mas sim a de retratá-los de acordo com os critérios que ele julgava relevantes para seus intentos.

O modo como de Bry representou a anatomia humana também é significativo de sua postura diante dos indígenas. Na imagem acima, eles são retratados totalmente nus (à exceção do líder), o que remeteria à noção de inocência e pureza. Belluzzo reporta este elemento à obra de Jean de Léry, que mostra o estado natural como uma "verdade essencial" oposta ao artificialismo da sociedade europeia. Para a autora, de Bry e o pastor huguenote: "parecem ter apreço pela simplicidade do nu, pelo nu como virtude" ${ }^{41}$. Entretanto, apesar de nus, não há como distinguir fisicamente indígenas e espanhóis ${ }^{42}$. Segundo Freire, era necessário que os indígenas fossem retratados iguais aos europeus para que não houvesse dúvida de que se tratavam de seres humanos. Esta forma de representar os corpos reforça

\footnotetext{
${ }^{39}$ Raminelli, op. cit., p. 35.

${ }^{40}$ Hans Staden, Duas Viagens ao Brasil, São Paulo, Edusp, 1974, p. 167.

${ }^{41}$ Belluzzo, op. cit., p. 54.

${ }^{42}$ Para comprovar a semelhança, Chicangana-Bayona trocou a cabeça de um índio com a de Hans Staden. Chicangana-Bayona, op. cit., 2006, p. 20.
} 
a afirmação feita por Theodoro de que, para o editor, todos são "irmãos". Tal representação obrigava ainda o europeu a ver-se no lugar do "outro", o que, em casos como o das imagens que enfocam a violência espanhola, certamente causava um maior impacto entre os leitores protestantes.

Não apenas os corpos eram usados como forma de aproximar índios e europeus, mas também suas ações, o que fica evidente em outras ilustrações feitas por de Bry para a Viaje al Río de la Plata.

Ilustração 2 - Theodore de Bry, Americae Pars VII, Frankfurt, 1599

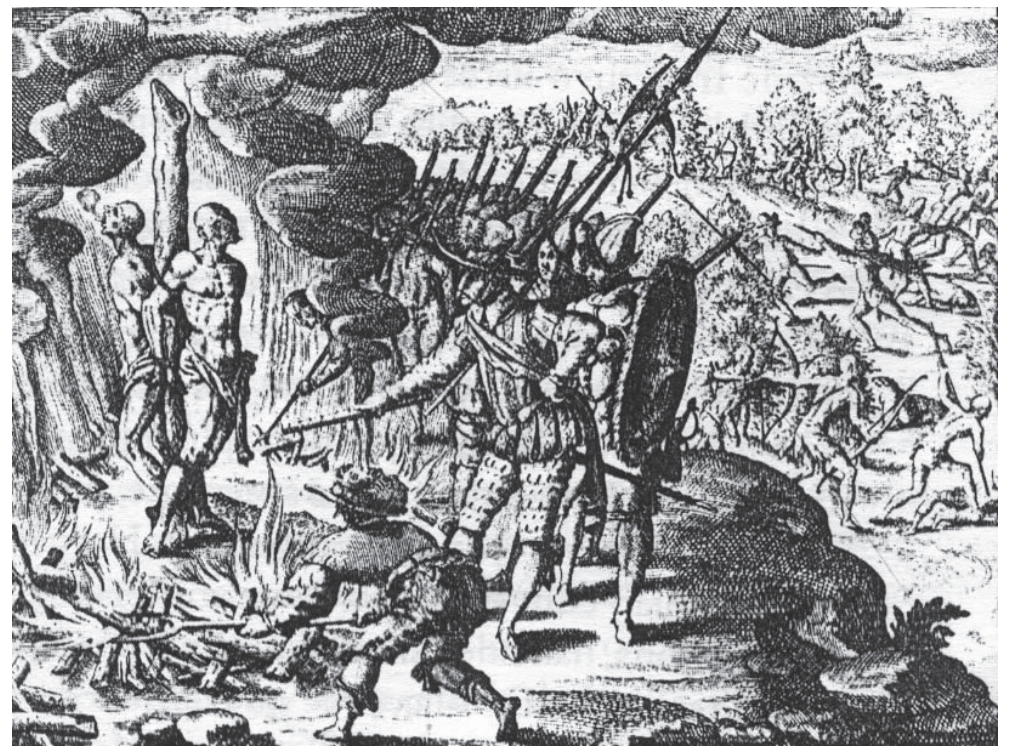

A cena acima (ilustração 2) foi incluída na obra próximo ao trecho em que Schmidl descreveu a emboscada feita pelos Naperú e Payaguá, que atacaram "como perros hambrientos a los cristianos y los mataron, que ninguno se salvó". $\mathrm{O}$ cronista afirmou ainda que ele e os espanhóis ficaram sabendo do ataque através de um escravo nativo que havia conseguido escapar, mas não acreditaram até um grupo aliado ter capturado alguns inimigos ${ }^{43}$.

\footnotetext{
43 "Se les dió tal tormento que los Payaguás debieron confesar y declararon que bien fuere verdad que ellos habían matado a los cristianos. Así tomamos los Payaguás y los condenamos y se les ató a ambos contra un árbol y se hizo una gran fogata desde lejos. Así se quemaron con el tiempo". Schmidl, op. cit., pp. 84-85.
} 
Nesta gravura, percebemos que o editor retratou o ataque indígena em segundo plano, dando destaque à fogueira e ao líder espanhol, que, em postura similar à ilustração anterior, ordena a morte dos nativos. Contudo, o que mais chama a atenção é a postura dos condenados. Enquanto o da direita está virado diretamente para o leitor, com seu rosto desfigurado pelo sofrimento, o segundo olha para o céu com a boca aberta, aparentemente fazendo uma prece. Certamente para os leitores protestantes a imagem de seres humanos queimados em fogueiras enquanto rezavam remetia aos autos de fé. Esta aproximação entre o sofrimento indígena e o dos reformados reforçaria, mais uma vez, a intenção de estimular a ação protestante no Novo Mundo para trazer a "verdadeira religião" aos nativos que, assim como na Europa, estavam sendo perseguidos pelos católicos espanhóis.

Para a análise desta imagem, torna-se necessário retornarmos às gravuras feitas por de Bry para a Brevísima Relación. Em várias delas, os indígenas, enquanto estão sofrendo os tormentos descritos por Las Casas, também são representados "como se estivessem rezando". Para Freire, a utilização de tais recursos provém do próprio "repertório do mundo católico, o que provoca o reconhecimento imediato e a indignação" ${ }^{44}$. Outros elementos também relacionam as ilustrações presentes na Viaje al Río de la Plata com as existentes na obra do dominicano: em várias delas os nativos são menores que os europeus e, nas duas edições, existem espanhóis atiçando o fogo que queima os indígenas. Este recurso já havia sido utilizado nas ilustrações presentes no terceiro volume da coleção, só que, nelas, são os índios que avivam as chamas das fogueiras para acelerar a preparação dos corpos dos inimigos para o ritual antropofágico. Nestas imagens, este elemento é utilizado para mostrar a avidez dos nativos por carne humana, já em Schmidl e Las Casas, tal recurso foi empregado como forma de tentar aproximar a destruição provocada pelos espanhóis a este bárbaro costume indígena.

A partir das relações identificadas entre as ilustrações presentes em diferentes relatos, fica evidente que de Bry buscava unificar o sentido de obras muito diversas entre si. Dessa forma, as gravuras presentes nos livros de Schmidl e Las Casas retratam temas semelhantes e, muitas vezes, a partir dos mesmos elementos: a crueldade dos espanhóis atacando os inocentes indígenas que os recebem pacificamente para, logo depois, serem torturados e mortos. A comparação entre diferentes obras permite ainda observarmos que o editor estabeleceu um "reper-

\footnotetext{
${ }^{44}$ Freire, op. cit., p. 105.
} 
tório comum", que se repete (como o cabelo "tonsurado" dos nativos). Mas, outras vezes, os mesmos elementos foram utilizados para produzir o efeito contrário, como a imagem do fogo sendo atiçado pelos indígenas que, na Viaje al Río de la Plata, é repetido, só que, agora, entre os espanhóis. Procedimento semelhante ocorre na última gravura feita por de Bry para a obra de Schmidl (ilustração 3). Nela, elementos que eram utilizados para representar os costumes bárbaros dos indígenas estão presentes entre os europeus.

Ilustração 3 - Theodore de Bry, Americae Pars VII, Frankfurt, 1599

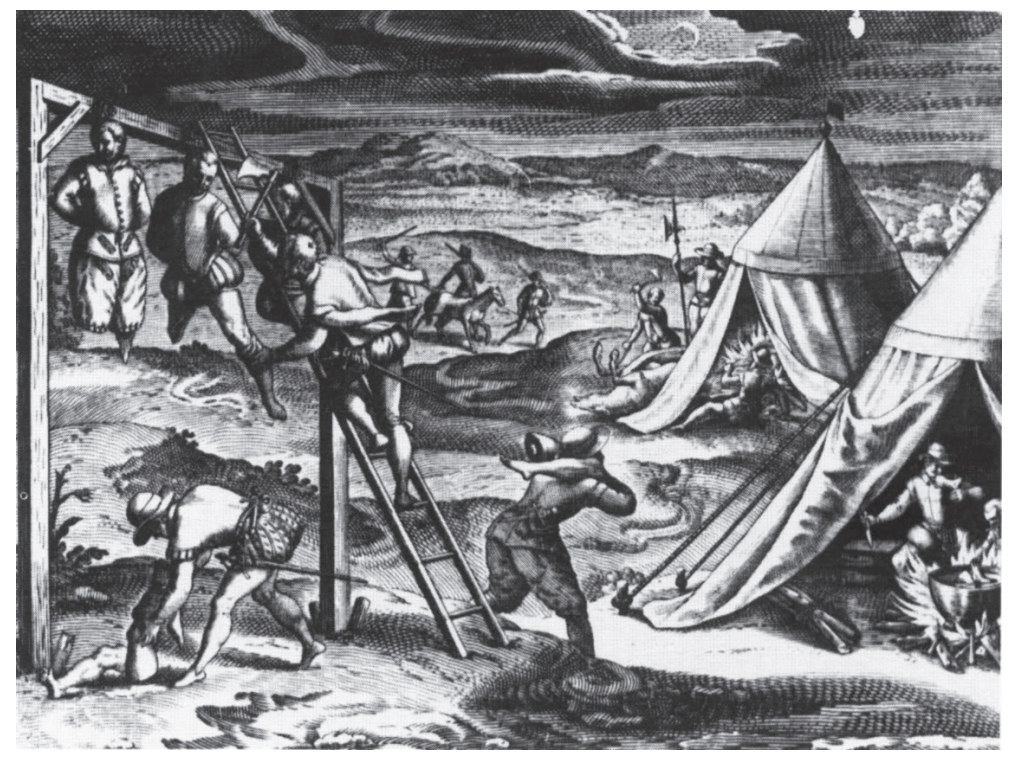

Esta gravura remete à passagem em que $S c h m i d l$ descreveu a primeira fundação de Buenos Aires. O cronista apontou que a fome extrema levou três moradores a matarem e comerem um cavalo da expedição, sendo, por isso, condenados à forca. Após a execução, seus corpos foram mutilados por outros espanhóis para servirem de alimento ${ }^{45}$.

\footnotetext{
${ }_{45}$ "Fue tal la pena y el desastre del hambre que no bastaron ni ratas ni ratones, víboras ni otras sabandijas; también los zapatos y cueros, todo tuvo que ser comido. Sucedió que tres españoles habian hurtado un caballo y se lo comieron a escondidas; y esto se supo; así se los prendió y se les dio tormento para que confesaran tal hecho; así fue pronunciada la sentencia que a los tres susodichos españoles se los condenara y ajusticiara y se les colgara en una horca. Así se cumplió esto y se los colgó en una horca (...) aconteció en la misma noche por parte de otros españoles que ellos han cortado los muslos y unos
} 
O primeiro aspecto que destacamos desta gravura é a ausência de indígenas. São retratados apenas soldados espanhóis, o que era algo incomum dentro das Grands Voyages. Outra característica relevante é a divisão de seu conteúdo em temporalidades diferentes. Nela, todo o trecho da descrição de Schmidl é representado, desde a captura e morte do cavalo até a mutilação dos cadáveres que são levados para uma tenda, onde são preparados e comidos. Esta divisão também pode ser identificada nas duas imagens anteriores (ilustrações 1 e 2). Assim como nesta ilustração, elas apresentam em sua parte superior, ao fundo, a ação que levou ao acontecimento retratado no primeiro plano (o convite do rei Jerú para que os espanhóis entrassem em suas terras; a emboscada preparada contra a expedição espanhola). A decisão de retratar uma sequência narrativa na ilustração (presente em autores como Albrecht Dürer) reforça seu caráter didático, facilitando e, simultaneamente, direcionando a leitura das passagens ilustradas.

A imagem do canibalismo espanhol pode ainda ser dividida em triângulos ${ }^{46}$. Em ambos os lados há elementos que secionam a cena (a escada encostada na forca e a corda da cabana) e acabam formando um grande triângulo na parte superior da imagem, que retrata a natureza desolada e as ações anteriores que levaram à condenação dos três soldados. Através desta repartição da ilustração em várias passagens, notamos que os elementos que a dividem convergem para o centro, direcionando o olhar do leitor para o ponto culminante da cena: um espanhol carregando uma perna humana ${ }^{47}$. A iluminação da gravura também direciona o olhar para o canibalismo espanhol. O ponto mais claro da cena é a forca com os corpos dos condenados iluminados pela Lua. Outro elemento atrai ainda a atenção (principalmente nas versões coloridas): as vivas chamas das fogueiras que preparam os corpos em contraposição com o exterior desolado.

Esta imagem da crônica de Schmidl ganha importância quando comparada com a décima gravura da Brevísima Relación (ilustração 4). Nela, além dos trabalhos forçados a que eram submetidos os indígenas, o editor retratou o canibalismo, que foi

pedazos de carne del cuerpo y los han llevado a su alojamiento y comido. También ha ocurrido entonces que un español se ha comido su propio hermano que estaba muerto". Schmidl, op. cit., pp. 48-50.

${ }^{46}$ Este mesmo procedimento foi utilizado por Freire ao analisar as gravuras feitas por Theodore de Bry para integrar sua edição da Brevísima Relación de Las Casas. Freire, op. cit.

${ }^{47}$ Para Lestringant, esta forma de dispor os elementos representaria um espiral, onde um erro (matar um cavalo para comê-lo) gera outro maior (a antropofagia), que se repete indefinidamente. Apud Duchet, op. cit., p. 101. 
representado de modo muito semelhante às ilustrações presentes no volume dedicado à obra de Hans Staden: como a presença da grelha com corpos humanos e a técnica utilizada pelos Tupinambá para abrir o cadáver do condenado a partir de um corte na coluna.

Há também a inclusão de uma espécie de "mercado" antropofágico, uma cabana onde dois espanhóis colocam à venda pedaços de corpos humanos a duas indígenas que, em troca, oferecem um colar. Apesar de não dar destaque em sua obra, Las Casas descreveu a antropofagia indígena e chegou a afirmar que os espanhóis consentiam com este bárbaro costume. Entretanto, em nenhum momento há menção a um possível comércio de carne humana. Tal inclusão, dessa maneira, aumentava o teor da crítica aos espanhóis, que não apenas permitiam, mas também estimulavam e obtinham lucros com esta prática. Ilustrada simultaneamente à obra do dominicano, a Viaje al Río de la Plata apontaria um estágio ainda maior de degradação: os espanhóis, ao invés de combaterem, estariam agora também adotando o canibalismo ${ }^{48}$.

\section{Ilustração 4 - Theodore de Bry, Tyrannies et Ceruautez des espagnols, Frankfurt, 1599}

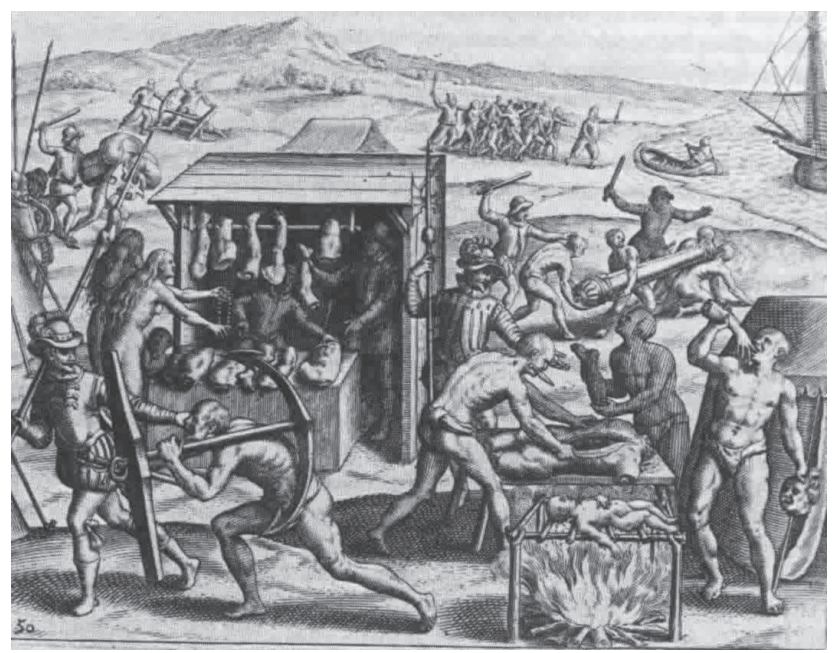

\footnotetext{
${ }^{48}$ A ilustração deste trecho da crônica também se relaciona com a obra de Jean de Léry, presente no terceiro tomo das Grands Voyages. A bárbara atitude dos espanhóis seria oposta ao comportamento dos protestantes, uma vez que Léry indicou em sua narrativa que, durante o retorno à Europa, ele e outros reformados sofreram com a escassez de alimentos, chegando a lançarem "olhares denunciadores da nossa disposição antropofágica", porém, nunca recorreram a tal recurso devido ao "temor a Deus". Jean de Léry, Viagem à Terra do Brasil, São Paulo, Edusp, 1980, pp. 264-265.
} 
Outro elemento relevante da gravura presente na edição de Schmidl é o interior da cabana, onde os pedaços dos corpos estão sendo preparados. A imagem retrata um espanhol mordendo o pé de um dos condenados enquanto o outro observa o caldeirão que prepara os alimentos. Os dois homens são representados a partir de modelos presentes nas ilustrações dos Tupinambá da narrativa de Staden. Com exceção das roupas, as posturas de espanhóis e indígenas são iguais. Contudo, a presença desta imagem junto com as outras três dão outros significados a estas aproximações. Enquanto os espanhóis comem carne humana por fome, os indígenas a utilizam em seus rituais, o que pode ser observado claramente na capa dos dois volumes da coleção (ilustração 5).

Ilustração 5 - Theodore de Bry, Americae Pars VII, Frankfurt, 1599

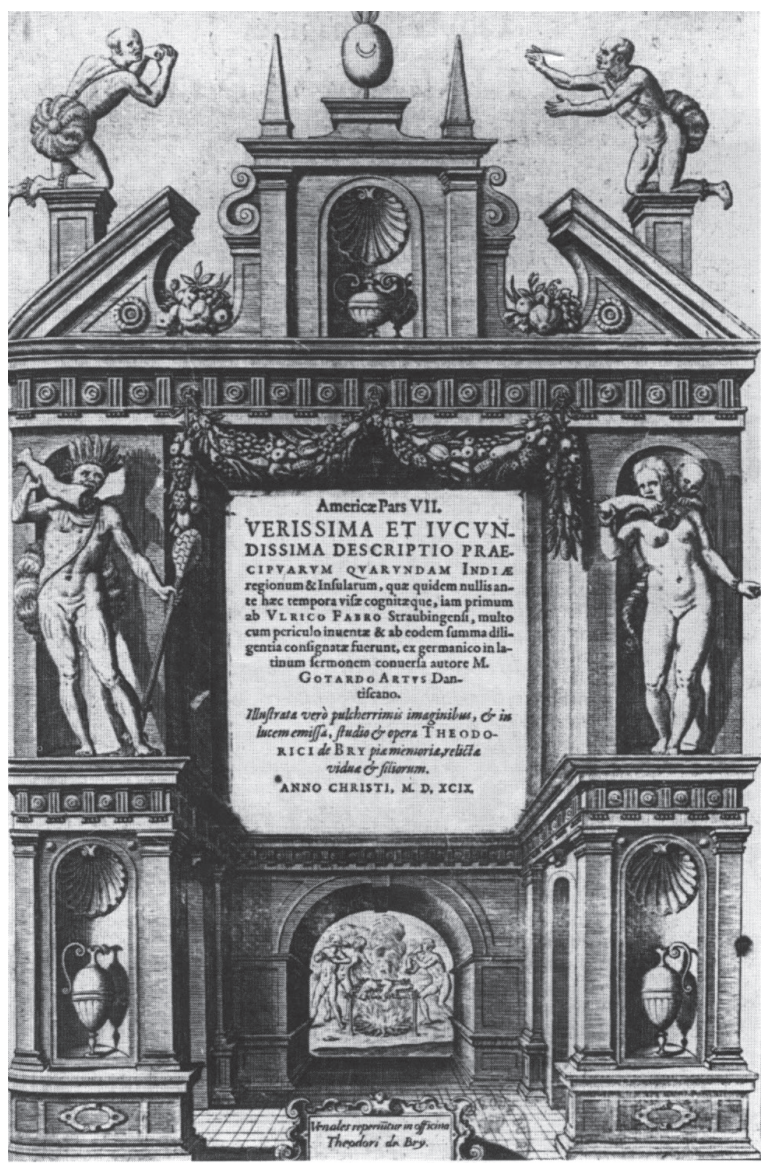


Voltando à análise da página de apresentação dos três cronistas, que apresentam apenas os títulos alterados, percebe-se que de Bry utilizou elementos cristãos para representar os nativos. Além do festim antropofágico e do casal que se alimenta de membros humanos, há a inclusão de um objeto na parte superior da imagem que é buscado por dois índios ajoelhados em postura suplicante. É importante observarmos que o alto das ilustrações era recorrentemente utilizado pelo editor como espaço privilegiado para retratar a idolatria ${ }^{49}$. Dessa maneira, notamos que a ilustração relaciona o canibalismo e a idolatria.

Esta aproximação foi tomada por diversos autores como uma mudança nos rumos das Grands Voyages. Raminelli apontou que, ao analisar a coleção, Bernadette Bucher identificou uma alteração no conteúdo das ilustrações a partir do terceiro volume, onde teria se iniciado "um processo de demonização dos americanos, destacando-se o canibalismo e os costumes exóticos. As gravuras reproduziam o cotidiano e os hábitos dos Tupinambá e pretendiam recriar graficamente uma atmosfera de horror, povoada por canibais e seres demoníacos" ${ }^{\text {" }}$. Seguindo esta interpretação, a inclusão desta ilustração na obra de Schmidl seria uma forma de reforçar os aspectos bárbaros dos indígenas americanos mesmo que o relato abordasse outra região do continente. No entanto, a partir dos argumentos de Janice Theodoro, tentaremos apontar outras interpretações.

O volume inicial das Grands Voyages possui uma ilustração do casal original (ilustração 6) claramente inspirada no quadro Adão e Eva ou A Queda do Homem, de Albrecht Dürer: ambas apresentam Adão com postura semelhante diante da árvore do fruto proibido ${ }^{51}$. Entretanto, diferentemente da imagem de Dürer, de Bry representou a parte superior da serpente como uma mulher que, apesar do rosto jovem, apresenta os seios caídos ${ }^{52}$. Um elemento que era comu-

\footnotetext{
${ }^{49}$ Enquanto o frontispício do quarto volume mostra os nativos adorando um ser monstruoso, o da quinta parte retrata, no mesmo local, uma cruz sendo fincada no Novo Mundo, o que poderia transmitir uma noção de progresso da fé cristã, uma vez que ambas são dedicadas ao relato de Benzoni.

${ }^{50}$ Ronald Raminelli “Theodore de Bry”, Ronaldo Vainfas, Dicionário do Brasil Colonial (1500 1808), Rio de Janeiro, Objetiva, 2000, p. 546.

${ }^{51}$ As semelhanças existentes entre as imagens de Albrecht Dürer e Theodore de Bry foram analisadas em: Chicangana-Bayona, op. cit., 2006, pp. 15-47.

${ }^{52}$ A utilização dos seios caídos como marca dos costumes bárbaros dos indígenas foi analisada por Bucher. Segundo Chicangana-Bayona, a autora "hace una lectura de estas imágenes como degradación, punición y condenación de los indios del Nuevo Mundo, lectura compartida por Belluzzo
} 
mente associado à degeneração do corpo e da alma das velhas antropófagas tupinambás também está presente na árvore do Paraíso.

\section{Ilustração 6 -Theodore de Bry, Americae Tertia Pars, Frankfurt, 1592}

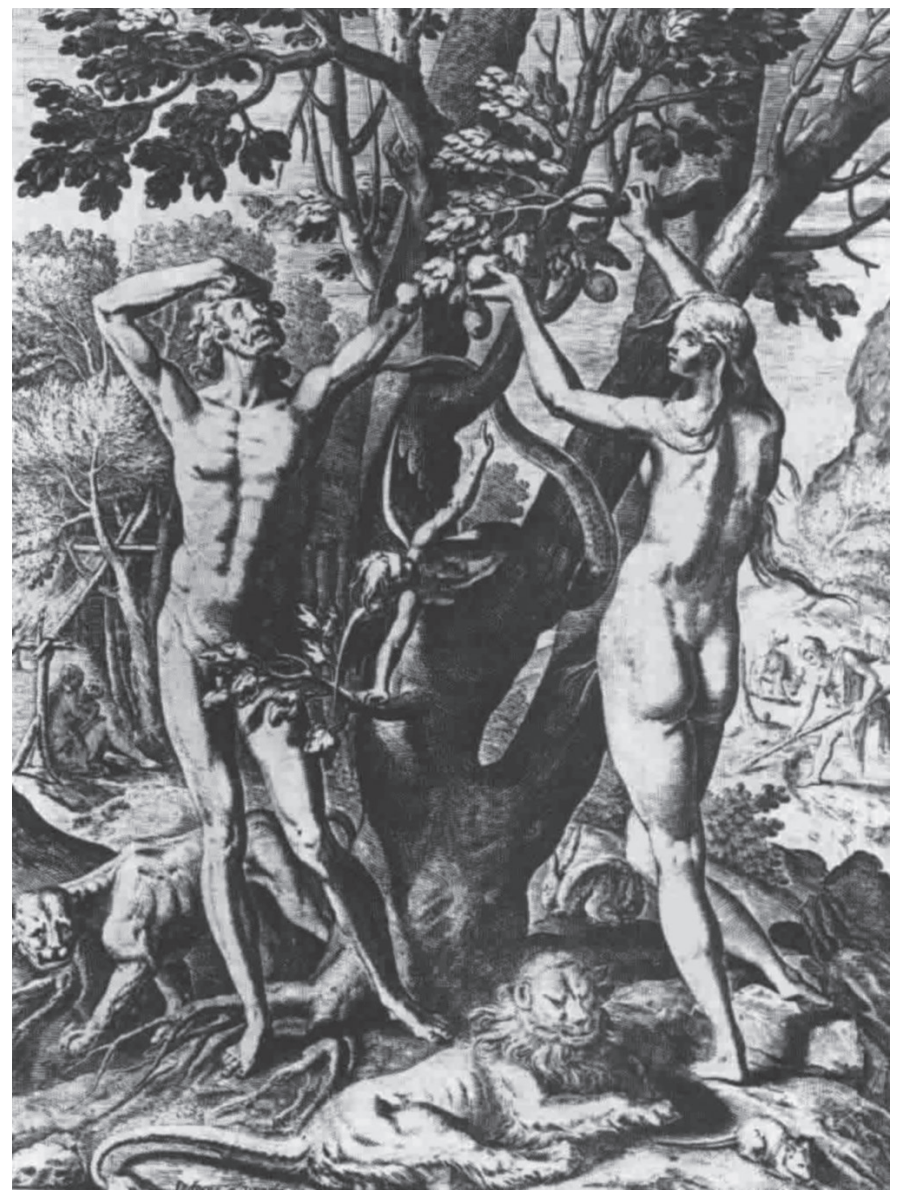

Segundo Ziebell, a representação do casal original nas coleções de narrativas de viagens estaria relacionada à ascensão de uma nova concepção: "o tema da unidade do gênero humano viria a substituir, dentro das coleções, o tema

y Raminelli en lo que se refiere a las viejas antropófagas tupinambá, mientras que Baumann cree que las formas aberrantes en Theodoro de Bry no significan solo degradación y más bien indican la posibilidad de transformación" Yobenj Aucardo Chicangana-Bayona, "El festín antropofágico de los indios Tupinambá en los grabados de Theodoro de Bry, 1592", Fronteras de la Historia, n. 10, Bogotá, 2005, p. 57. 
cosmográfico da unidade do mundo"53. Processo este, visível através da análise das representações dos corpos indígenas. O casal Tupinambá retratado comendo uma perna e um braço humano ao lado dos títulos das crônicas de Staden, Léry e Schmidl (ilustração 5) também é representado a partir dos cânones utilizados por Dürer. Além da mesma disposição corporal, os membros dos indígenas estão em posições muito semelhantes às do casal original, porém, enquanto Adão tem suas "vergonhas" cobertas pela vegetação e está segurando um galho de árvore, o tupinambá está nu, segurando uma perna humana e a ibirapema.

As semelhanças entre uma cena de antropofagia com a imagem do casal original reforçam a noção de que os habitantes do Novo Mundo, apesar de possuírem alguns costumes bárbaros, também são descendentes de Adão. A origem comum deixaria nos nativos, além do pecado original, a "semente de religião" ${ }^{54}$ que vários autores do período procuravam. Ela seria a prova de que eles poderiam ser convertidos ao cristianismo, o que é reforçado pela postura dos dois índios retratados na parte superior do frontispício que, mesmo desconhecendo a verdadeira religião, apresentam atitudes e posturas semelhantes às dos cristãos. Assim, a reutilização da capa de Staden e Léry no volume de Schmidl seria uma forma de enfatizar não a barbárie indígena, mas alguns aspectos que os aproximariam dos cristãos.

Por fim, torna-se necessário observarmos alguns aspectos da crônica de Schmidl que foram omitidos nas gravuras feitas por de Bry. Como visto acima, o canibalismo era algo que atraía a atenção do público leitor, sendo comumente utilizado por católicos e protestantes como argumento para atacar o comportamento do adversário. Contudo, o volume dedicado ao relato de Schmidl permite observarmos melhor a postura do editor diante desta prática. Apesar da repetição do frontispício do volume com as crônicas de Staden e Léry, nenhuma das imagens inspiradas na Viaje al Río de la Plata incluiu esta prática entre os índios, ainda que o cronista tenha apontado a existência de certos grupos, como os Carijó e os Tupi, que se alimentavam dos corpos de seus inimigos ${ }^{55}$. Nes-

\footnotetext{
${ }^{53}$ Ziebell, op. cit., p. 116.

${ }^{54}$ Esta expressão foi utilizada por Jean de Léry para confirmar a possibilidade de introdução da "verdadeira fé" na América: "mostrarei como essa semente de religião (se é que as práticas dos selvagens possam merecer tal nome) brota e não se extingue neles, não obstante as trevas em que vivem”. Léry, op. cit., p. 208.

${ }_{55}$ "Cuando estos susodichos Carios hacen la guerra contra sus enemigos, entonces a quien de estos enemigos agarran o logran, sea hombre o mujer, sea joven o vieja, sean niños, los ceban como aquí en
} 
tas ilustrações a antropofagia é retratada apenas entre os espanhóis, enquanto os nativos são representados caçando animais para realizarem um banquete de recepção. Raminelli afirmou que tal omissão não era apenas intencional como era algo recorrente no século XVI. Segundo o autor, atenuar a antropofagia indígena servia como arma contra os católicos espanhóis: "conceber os ameríndios como bons selvagens era uma forma engenhosa para denunciar as atrocidades praticadas pelos espanhóis no Novo Mundo" ${ }^{36}$. Dessa forma, percebe-se que a análise dos "silêncios" também é importante para compreendermos as ilustrações das Grands Voyages.

\section{Conclusão}

Em nossa análise, não pretendemos minimizar o impacto da antropofagia indígena nas gravuras feitas por Theodore de Bry. Através de suas ilustrações fica evidente que o editor considerava tal prática como algo que deveria ser combatido e eliminado o mais rapidamente possível. Porém, a coleção também participava dos debates sobre a conversão dos nativos. A aproximação do canibalismo com a imagem da "queda do homem" reforçava a ideia de que, apesar de bárbara, a ingestão de carne humana era um pecado e, dessa forma, poderia ser redimida através do arrependimento e da mudança de comportamento, uma vez que eles também eram descendentes do casal original criado por Deus.

Dessa maneira, a utilização de elementos como a representação de indígenas e europeus com corpos iguais, as posturas e comportamentos "cristãos" de alguns nativos, a repetição dos cabelos "tonsurados" e das recepções pacíficas em vários volumes, entre outros, traziam consigo a defesa de que a catequização não era apenas possível, mas também desejada pelos habitantes do Novo Mundo. Para que esse objetivo fosse alcançado era necessário que os encarregados de apresentarem a "verdadeira religião" aos gentios não agissem como os católicos espanhóis, que acabaram adotando atitudes e costumes que, a princípio, deveriam combater.

Por fim, torna-se necessário ressaltar que não buscamos apontar como o público leitor do período interpretou essas ilustrações, mas sim quais aspectos Theodore de Bry e seus descendentes consideraram relevantes ressaltarem ou

esta tierra se ceba un cerdo, pero si la mujer es algo linda, la conserva un año o tres. Cuando entonces esta mujer en un poco no vive a gusto de él, entonces la mata y la come”. Schmidl, op. cit., pp. 70-71.

${ }^{56}$ Raminelli, op. cit., 1996, p. 49. 
omitirem em suas edições dos relatos de viajantes. Processo este denominado por Roger Chartier como um "trabalho de adaptação", que busca, através de diferentes estratégias, impor uma ortodoxia do texto, sem, entretanto, anular a "irredutível liberdade dos leitores" ${ }^{\text {"5 }}$.

${ }^{57}$ Chartier, op. cit., 1990, p. 123. 